\title{
Effect of screw position on bone tissue differentiation within a fixed femoral fracture
}

\author{
Saghar Nasr ${ }^{1,2}$, Stephen Hunt ${ }^{1,3}$, Neil A. Duncan ${ }^{1,3,4^{*}}$ \\ ${ }^{1}$ McCaig Institute for Bone and Joint Health, Calgary, Canada \\ ${ }^{2}$ Department of Mechanical \& Manufacturing Engineering, Schulich School of Engineering, University of Calgary, Calgary, Canada \\ ${ }^{3}$ Department of Orthopedic Surgery, University of Calgary, Calgary, Canada \\ ${ }^{4}$ Department of Civil Engineering, Schulich School of Engineering, University of Calgary, Calgary, Canada \\ Email: "duncan@ucalgary.ca
}

Received 30 October 2013; revised 28 November 2013; accepted 17 December 2013

Copyright (C) 2013 Saghar Nasr et al. This is an open access article distributed under the Creative Commons Attribution License, which permits unrestricted use, distribution, and reproduction in any medium, provided the original work is properly cited.

\begin{abstract}
Plate and screw constructs are routinely used in the treatment of long bone fractures. Despite considerable advancements in technology and techniques, there can still be complications in the healing of long bone fractures. Non-unions, delayed unions, and hardware failures are common complications observed in clinical practice following open reduction and internal fixation of fractures [1]. Potential causes of these adverse clinical effects may be disruptive to the periosteal and endosteal blood supply, stress shielding effects, and inadequate mechanical stability. The goal of the present study was to explore the effect of screw position on the fracture healing and formation of new bone tissue with mechanoregulatory algorithms in a computational model. An idealized poroelastic 3D finite element (FE) model of a femur with a $5 \mathrm{~mm}$ fracture gap, including a plate-screw construct was developed. Nineteen different plate-screw combinations, created by varying the number and position of screws within the plate, were created to identify a construct with the most favourable attributes for fracture healing. The first phase of the study evaluated constructs through mechanical stress analyses to identify those constructs with high loadsupport capability. The second phase of the study evaluated healing and bone formation with a biphasic mechanoregulatory algorithm to simulate tissue differentiation for fixation within selected constructs. The results of our analysis demonstrated a 4-screw symmetrical construct with the largest distance between screws to provide the most favourable balance of stability and optimized conditions to promote fracture healing.
\end{abstract}

\footnotetext{
"Corresponding author.
}

Keywords: Femoral Fracture; Internal Fixation; Screw Number; Screw Position; Tissue Differentiation; Finite Element Analysis

\section{INTRODUCTION}

The treatment of long bone fractures is a significant health problem, particularly for femoral fractures [2-5]. Although bone has outstanding mechanical properties and a remarkable ability to heal, in some cases healing is impaired or delayed [6,7]. Internal fixators have been used as the most common treatment technique for open and closed fractures $[3,8-10]$. Despite the advent of intramedullary fixation, there are still clinical indications for plating of long bone fractures (e.g., pulmonary complications, damage control orthopaedics, revision procedures, absence of X-ray, obliterated canal, small canal and periarticular fractures). The main goals of any orthopaedic fixation technique are to maintain anatomic alignment, provide stability of the fracture to facilitate healing, and increase load bearing to facilitate rehabilitation [11]. Internal fixation is commonly a fracture spanning plate with a combination of screws through the plate. The two main drawbacks of internal fixations are: 1) disruption of blood supply, and 2) shielding the underlying bone and fracture gap from mechanical stresses. To overcome vascularisation issues and surgical exposure, orthopaedic hardware is installed with utmost care to protect soft tissues, and minimize soft tissue stripping in order to lessen devascularisation of bone $[3,10,11]$. One technique to minimize vascular damage to bone includes reducing the number of screws used to anchor the plate to bone [12]. Reducing the number of screws may not significantly affect the structural stiffness of the fracture, but may increase the strain at the fracture site [12]. Furthermore, the mismatch between bone and plate stiffness 
can cause stress shielding which may lead to complications of bone resorption and focal osteoporosis [13-16]. A comprehensive and algorithmic approach to selecting screw type and configuration may minimize the deleterious effects of screw installation, provide mechanical and biological insight on the contributions of screw type and position, and provide an evidence-based justification for surgical technique. It is our hope that this will provide the basis for further advancement of open reduction and internal fixation techniques for fracture care.

Empirical and computational data support that mechanical stimulation of bone is an important factor in bone healing [17-20]. A number of different mechanoregulatory algorithms have been developed and are generally classified into 1) single-solid phase and 2) biphasic algorithms. These algorithms are regulated by one or two mechanical stimuli, which may include interfragmentary gap movement, octahedral shear strain, hydrostatic stress, fluid velocity and fluid shear stress [17,18,21-24]. Isaksson et al. (2006) compared tissue differentiation patterns in a finite element model (FE) of an ovine tibia implementing different proposed algorithms [17]. The computational predictions were then validated against experimental observations in vivo. The biphasic algorithm proposed by Lacroix and Prendergast (2002) was found to most closely model experimental observations [17]. The biphasic algorithm has been widely used to investigate skeletal tissue repair [17,23, 25-32], and thus we selected this biphasic algorithm to predict tissue differentiation in our analyses.

Prediction of the bone mechanobiology conditions at the fracture site has been previously investigated to optimize fixation constructs [33-35]. Kim et al. (2012) used a single-solid phase mechanoregulatory model regulated by deviatoric tissue strain to predict tissue differentiation in a 3D idealized fracture tibia using plates with different material properties. The carbon/epoxy composite plate was found to highly promote tissue differentiation [35]. Son and Chang (2013) used the same single-solid phase mechanoregulatory algorithm as Kim et al. (2012) to predict the healing process in idealized 3D tibia models with different oblique fractures [34]. It was observed that the plate material (stiffness) that should be used was highly dependent on the angle of the fracture. The carbon/epoxy composite plate had the highest healing rate when the fracture angle was lower than $25^{\circ}$, whereas for higher angles, the glass/polypropylene composite plate led to more bone formation [34].

Dubov et al. (2011) explored optimal cable-screw positioning in femoral fracture models using an eight screw-hole plate and six screws (using 2 screws in the proximal femur). The stability and biomechanical performance of different cable-screw constructs were computationally predicted, and then validated against ex- perimental results [10]. The femur was modelled as an elastic material and quasi-static loads were applied to one end while the other end was fixed. The construct experiencing the least von Mises stress values at the screws, plate and bone was selected as the optimal structure. However, to the best of our knowledge, no studies have been performed to predict tissue differentiation within the fracture for different bone-screw assemblies. With the advancement of minimally invasive surgical techniques, optimal screw configuration may influence surgical technique and equipment design. The prevalence of orthopaedic joint replacements has resulted in a significant increase in the incidence of periprosthetic fractures. The limited space and bone available for fixation with plate and screw constructs present the orthopaedic surgeon with considerable operative challenges. Better understanding of the optimal screw number and position has the potential to advance fracture care in these situations $[36,37]$.

Improper screw spacing and number may result in non-ideal mechanical conditions and consequently, disrupted healing and cell apoptosis [38-40]. Hence, prediction of the mechanical environmental and tissue differentiation may help us to obtain a better understanding of the optimal screw number and position. This knowledge can improve internal fixation techniques to better prevent non-unions and accelerate the healing process. Therefore, the objective of this study was to evaluate the effect of internal fixation configuration on the mechanical stability and the healing progression for a transverse femoral fracture. We varied the screw positions within a standard orthopaedic plate installed across a $5 \mathrm{~mm}$ fracture gap [10] and identified a construct that provided the most favourable mechanical and mechanobiological conditions for healing. This systematic computational analysis can contribute to an evidence-based justification of optimal plate-screw combination and can provide important mechanical performance guidelines for surgical technique and product selection.

\section{METHODS}

An idealised 3D finite element model of a human femur with a $5 \mathrm{~mm}$ fracture gap [10] was developed (ABAQUS v6.11, Simulia, USA) to represent a transverse fracture in the femoral shaft (Figure 1). The femur was modelled as an outer cortical layer and an inner trabecular core with diameters of $32 \mathrm{~mm}$ and $16 \mathrm{~mm}$, respectively [10]. The fracture gap was assumed to be initially filled with a scaffold consisting of stem-cell-seeded granulation tissue. To model the internal fixation, a $3.5 \mathrm{~mm}$ Low ContactDynamic Compression Plate (LC-DCP, Synthes, Paoli, PA, USA) containing eight screw-holes with uniform spacing was created (Figure 1). LC-DCPs are mainly used for fractures in long bones and have minimal direct 


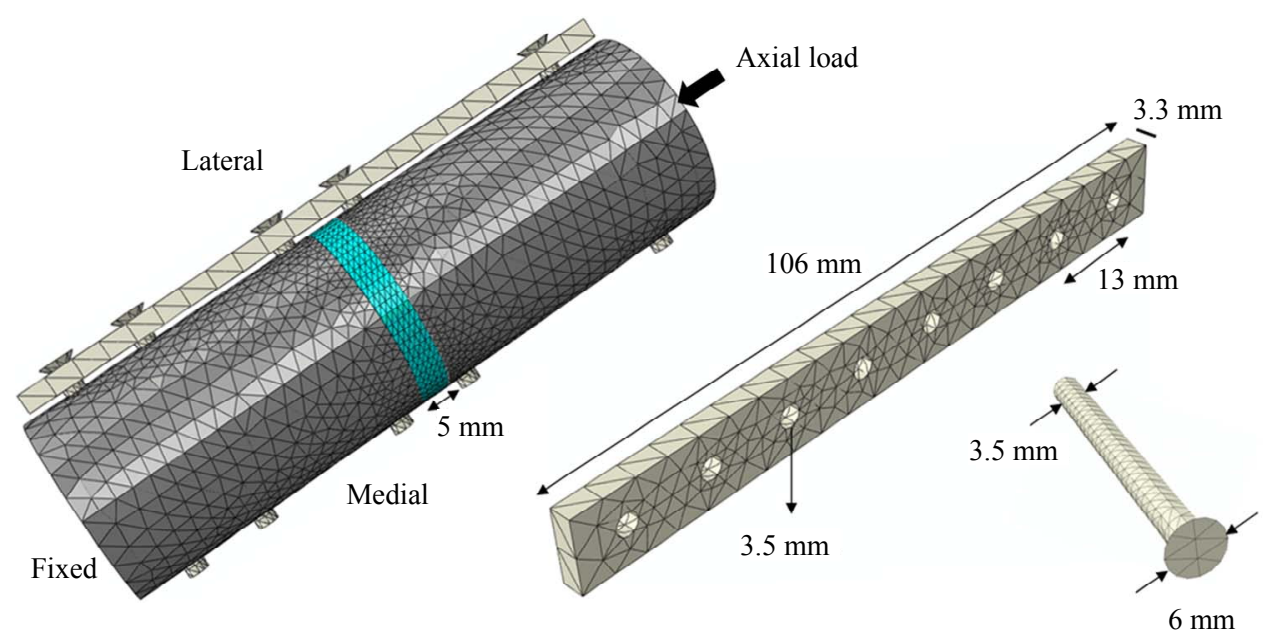

Figure 1. Finite element representation of the bone, plate and screws assembly.

contact with underlying bone to preserve blood supply $[14,41]$. To accommodate the irregular surface of bone, the mismatch between the curvature of the bone and the plate, and interposed fascia and soft tissue between the plate and bone (commonly observed in surgical exposures that minimize soft tissue insult in the zone of injury), we modelled our plate elevated $1 \mathrm{~mm}$ from the surface of the bone [42].

The distance between the hole centers was $13 \mathrm{~mm}$ (VS3041.08, Synthes, USA). Size-matched locking screws (VS301.038, Synthes, USA) with a diameter of $3.5 \mathrm{~mm}$ were modelled [3,11]. The plate and locking screws had lengths of $106 \mathrm{~mm}$ and $38 \mathrm{~mm}$, respectively (Figure 1). Both the screws and plate holes were fully threaded, and thus their contacting pairs (i.e. bone-screw and plate-screw) had negligible relative motion with respect to each other. Therefore, a tie constraint was defined between all contacting pairs (including bone-scaffold) to make the translational and rotational motions equal for each contacting surface. An axial compressive load, which is the predominant load in long bones $[43,44]$, was considered in our analyses. The distal end of the femur was completely constrained while a cyclic load was applied to the proximal end. According to the experimental study of Aranzulla et al. (1998), the weight bearing load to a fractured bone was reported to be $\sim 50 \%$ body weight (BW) at 6 weeks post fracture [45]. Patients generally limit their weight bearing on their affected extremity due to pain, the use of walking aids, and clinical direction from their surgeon to minimize the chances of premature hardware failure. Therefore, an average axial compression load of $350 \mathrm{~N}(\sim 50 \% \mathrm{BW})$ was used in our simulations to be representative of a typical orthopaedic post-operative protocol $[46,47]$. The plate-screw construct shifted the neutral axis of the bone toward the plate. Therefore, the axial compressive load also applied a marginal bending moment to the assembly (bone and in- ternal fixation).

The bone and scaffold were defined as isotropic and poroelastic materials, whereas the plate and screws were modelled as isotropic and linear elastic materials. Based on the experimental/numerical study of Papini et al. (2007), the Young's modulus (E) and Poisson's ratio (v), respectively, were defined as $16.7 \mathrm{GPa}$ and 0.3 for cortical; and $0.155 \mathrm{GPa}$ and 0.3 for trabecular bone, respecttively (Table 1). The permeability and void ratio were defined as $10-5 \mathrm{~mm}^{4} / \mathrm{Ns}$ [48] and 0.041 [49] for cortical bone and $0.37 \mathrm{~mm}^{4} / \mathrm{Ns}$ and 4.0 [26] for the trabecular bone, respectively (Table 1). The plate and screws were considered as 316 L medical-grade stainless steel (Synthes, Paoli, Pennsylvania, USA) with a Young's modulus and a Poisson's ratio of $193 \mathrm{GPa}$ and 0.3 , respectively (Table 1).

Cortical and trabecular bone were meshed using 4node linear tetrahedron pore pressure elements (C3D4P). The linear tetrahedral elements were selected over the quadratic elements to decrease the computational costs. The scaffold was meshed using 10-node modified quadratic tetrahedron pore pressure elements (C3D10MP). The plate and screw structures were meshed using 10-node quadratic tetrahedron elements (C3D10). Three meshes with increasing density $(62545,71763$ and 95175 elements) were created to assess mesh convergence. The average octahedral shear strain, fluid velocity and maximum displacement of the scaffold were considered for convergence analysis. The increase in the element number, from 62545 to 95175 , resulted in $\sim 0.6 \%$ difference for the average octahedral shear strain and maximum displacement, and $\sim 0.03 \%$ for the average fluid velocity. Hence, 62545 elements were considered adequate for an accurate estimation of the mechanical behaviour within the model.

Tissue differentiation within the scaffold was modelled using a biphasic algorithm based on octahedral shear 
Table 1. Mechanical properties of the tissue and internal fixation materials $[26,48,49]$.

\begin{tabular}{cccccccc}
\hline & \multicolumn{2}{c}{ Femur } & \multicolumn{2}{c}{ Scaffold } & \multicolumn{2}{r}{ Internal fixation } \\
\cline { 2 - 8 } & Cortical & Trabecular & Granulation & Fibrous tissue & Cartilage & Bone & Plate/Screw \\
\hline Young's modulus [GPa] & 16.7 & 0.155 & 0.0002 & 0.002 & 0.01 & $1-6$ & 193 \\
Poisson's ratio & 0.3 & 0.3 & 0.167 & 0.167 & 0.167 & 0.3 & 0.3 \\
Permeability [mm $\left.{ }^{4} / \mathrm{Ns}\right]$ & $10^{-5}$ & 0.37 & 0.01 & 0.01 & 0.005 & $0.1-0.37$ & - \\
Void ratio & 0.041 & 4.0 & 4.0 & 4.0 & 4.0 & 4.0 & - \\
\hline
\end{tabular}

strain $\left(\varepsilon_{o c t}\right)$ and interstitial fluid velocity $\left(v^{f}\right)[24,25]$ :

$$
S=\frac{\varepsilon_{\text {oct }}}{0.037}+\frac{v^{f}}{0.003} .
$$

High values for mechanical stimulus $(S)$ promote the differentiation of cells into fibrous tissues $(3<\mathrm{S}<6)$, intermediate values stimulate cartilage differentiation $(1$ $<\mathrm{S}<3)$, and low levels lead to formation of immature $(0.267<\mathrm{S}<1)$, and mature bony tissue $(0.011<\mathrm{S}<$ $0.267)$.

For each element, differentiation and the formation of bone tissue was simulated by a gradual change of material properties over time. The initial cellular tissue gradually differentiated into fibrous tissue, immature and mature cartilage, and immature and mature bone depending on the local mechanical environment. A user defined FORTRAN subroutine, USDFLD, was developed to update the material properties based on the average of computed mechanical stimulus $(\mathrm{S})$ in the previous 10 steps (weeks) [34,35]. In each step, the mechanical stimuli were calculated at the point of maximum loading, and a cyclic compressive load of $350 \mathrm{~N}$ was applied to the proximal end of femur. One loading step was considered as a surrogate for one week of healing [34,35], and the applied load represented the average load that was applied to the bone during one week of healing [34,35].

To investigate the effect of screw spacing on the mechanical stability of the fracture and bone healing process, nineteen distinct constructs were created (Figure 2). The models were composed of (a) eight screws: C1 (Figure 2); (b) seven screws: C2, C3; (c) six screws: C4, $\mathrm{C} 5, \mathrm{C} 6, \mathrm{C} 2 \mathrm{a}, \mathrm{C} 2 \mathrm{~b}, \mathrm{C} 3 \mathrm{a}$ and $\mathrm{C} 3 \mathrm{~b}$; (d) five screws: C4a, $\mathrm{C} 5 \mathrm{a}$ and C6a; (e) four screws: C4b, C5b and C6b; and (f) two screws: C7, C8 and C9 (Figure 2). Considering all models illustrated in Figure 2: (1) in each column, the number and location of screws in the proximal femur are held fixed, whereas variations are applied to the screws in the distal femur; (2) in the first two rows, the number and location of the screws in the distal femur are held fixed, whereas variations are applied to the screws in the proximal femur; and (3) the configurations of third and fourth rows are symmetric about the center line passing through the fracture zone. Note that each column in Figure 2 is called "a family of constructs" in the rest of the paper.

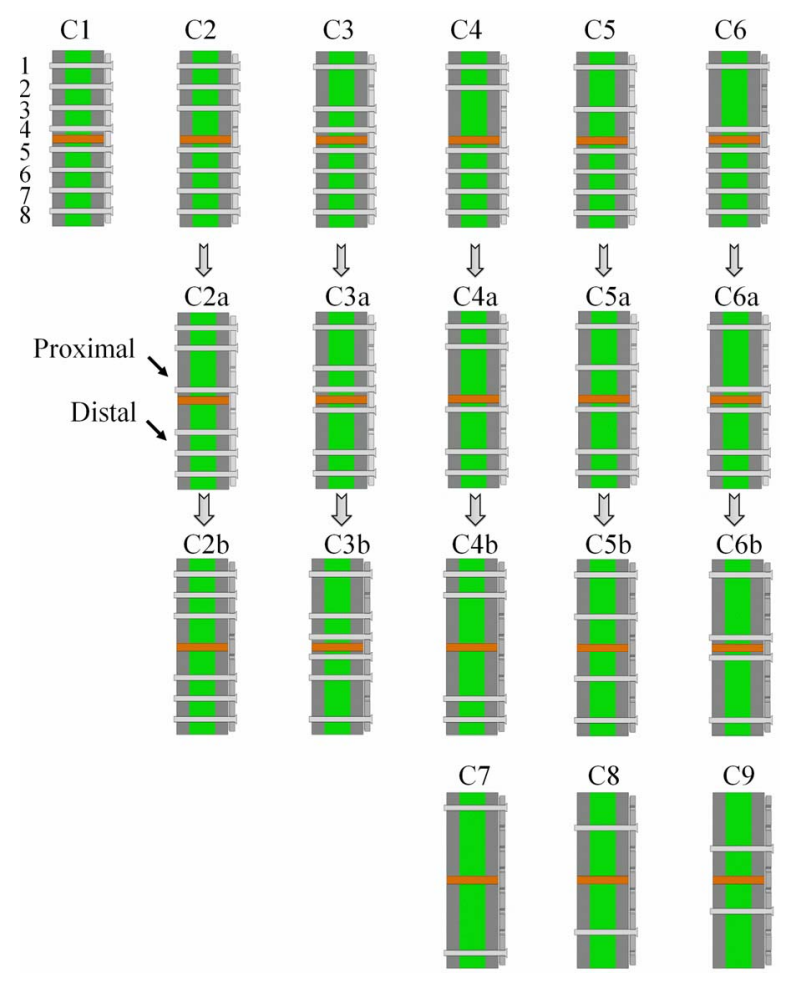

Figure 2. Constructs representing different screw combinations. The cortical bone, trabecular bone and scaffold are shown in dark grey, green and orange, respectively. The screws are numbered starting from the proximal end as shown in construct $\mathrm{C} 1$. The arrows show the sequential change in each family of constructs.

A number of experimental/numerical studies [50-53] have shown that bone fails by brittle fracture. Schileo et al. (2008) computationally predicted the location of cadaver femur fractures using the maximum principal stress, maximum von Mises stress and maximum strain criteria in comparison to experimental observations (i.e., the load-displacement curves and high-speed movies) [50]. Comparing the computational predictions to the experimental observations, they observed that the strain criterion better predicted the risk of bone fracture and its location [50]. In the present study, the maximum principal strain and von Mises criteria were both used to distinguish the models with lower risk of fracture and higher load-support capabilities [10,50,54]. Ultimate compressive and tensile strains of 0.0104 and 0.0073 , 
respectively, for bone were adopted from the experimenttal study of Bayraktar et al. (2004) [54]. Lastly, the bone was subjected to a cyclic compressive loading and bone formation was predicted implementing the biphasic mechanoregulatory algorithm into the nominated models with lower risk of failure (from phase I). Tissue distribution and average stiffness of the scaffold at the fracture gap were then compared in the nominated models over the healing period, and the optimal plate-screw construct with the best balance of stability and bone healing capability was selected.

\section{RESULTS}

\subsection{Mechanical Environment within the Internal Fixation, Femoral Bone and Fracture Site}

Stresses were in general higher in the screws compared to the plate. A maximal von Mises stress of $\sim 473 \mathrm{MPa}$ was found for the screws in the 4-screw construct C6b (fourth screw position), whereas it was only $226 \mathrm{MPa}$ for the surrounding plate (fourth screw-hole) (Figures 3(a) and (c)). The magnitude of von Mises stress within the plate was greatest between the lowermost screws in the proximal femur and the uppermost screws in the distal femur. For example, in construct $\mathrm{C} 6 \mathrm{~b}$ the region of maximum von Mises stress (i.e. 192 - $226 \mathrm{MPa}$, Figure 3(a)) was located between the fourth and fifth plate screw-holes. A stress concentration was observed in the vicinity of the screw-holes in the femoral bone, whereas the stress was almost uniformly distributed elsewhere (e.g. C6b, Figure 3(c)). The maximum femoral stress was found around the lowermost screw-hole in the proximal femur.

The construct that had every plate hole filled with a screw (C1), demonstrated increased overall stiffness and decreased magnitude of stress and strain compared to other constructs (Figures 4(a)-(d)). In contrast, constructs with only two screws (C7, C8, and C9) experienced significantly greater stress magnitudes, i.e. $\sim 490$ $550 \%$, compared to the fully-screwed femur (Figure 4(a)). However, the stress fields in $\mathrm{C} 1$ were not signifycantly different from those of 7-screw constructs (i.e. C2 and C3, Figure 4(a)). Consequently, since the stress distribution was insensitive between $\mathrm{C} 1, \mathrm{C} 2$ and $\mathrm{C} 3$, the numberof screws was reduced to six. The peak principal stress values in the femur were relatively higher in the 6-screw constructs with two screws above the fracture (i.e. $\mathrm{C} 4, \mathrm{C} 5$ and $\mathrm{C} 6$, Figure 4(a)) compared to the ones with three screws above the fracture (i.e. $\mathrm{C} 2 \mathrm{a}, \mathrm{C} 2 \mathrm{~b}, \mathrm{C} 3 \mathrm{a}$ and $\mathrm{C} 3 \mathrm{~b}$, Figure 4(a)). In each construct family (Family of $\mathrm{C} 2, \mathrm{C} 3, \mathrm{C} 4, \mathrm{C} 5$ and C6, Figure 4(a)); screw omissions resulted in marginal changes in the level of princepal stress in the femur (Figure 4(a)). For instance, for the construct family of $\mathrm{C} 5$ (i.e. $\mathrm{C} 5, \mathrm{C} 5 \mathrm{a}$ and $\mathrm{C} 5 \mathrm{~b}$ with 6,5 (a)

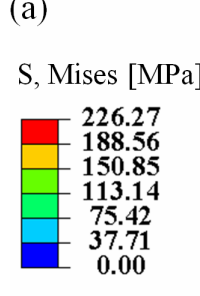

(c)

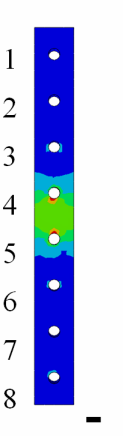

(b)
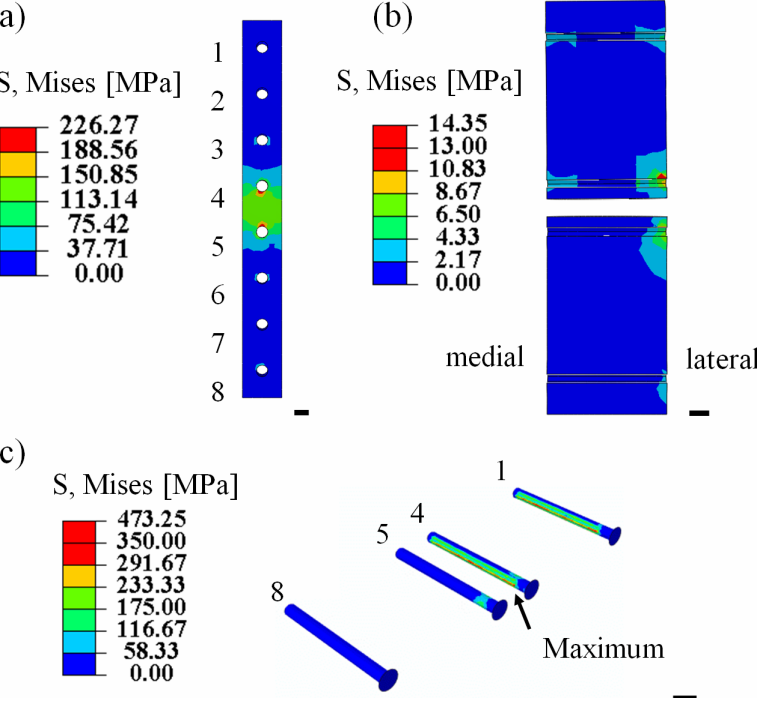

Figure 3. Distribution of von Mises stress within C6b construct: (a) Plate, (b) Femur and (c) Screws located at the first, fourth, fifth and eighth screw-holes. ( $a, b)$ The zone between the fourth and fifth screw-holes, located above and below the fracture gap, experienced higher stress magnitudes compared to the other holes. $(\mathrm{a}, \mathrm{b})$ The femur experienced less von Mises stress compared to the plate. (a, b) Stress concentration can also be observed around the femur screw-holes. The scale bars are $5 \mathrm{~mm}$.

and 4 screws), the maximum principal stress was 8653 $\mathrm{kPa}, 8779 \mathrm{kPa}$ and $9201 \mathrm{kPa}$ for C5, C5a and C5b, respectively (maximum difference was $\sim 6.3 \%$ ). However, the screw position resulted in a considerable difference in the stress magnitudes. For instance, the maximum principal stress was 9201 and $7610 \mathrm{kPa}$ for 4-screw constructs $\mathrm{C} 5 \mathrm{~b}$ and $\mathrm{C} 6 \mathrm{~b}$, respectively (maximum difference was $\sim 20.9 \%$ ).

Among the 4-screw constructs, the femur of C5b experienced larger principal strains compared to either $\mathrm{C} 4 \mathrm{~b}$ or C6b (Figure 5). The strain was lower within C6b and also more uniformly distributed throughout the length of the femur compared to $\mathrm{C} 4 \mathrm{~b}$ construct (Figures 5(a) and 5(c)). The maximum and minimum principal strains were lower than the limit values of the principal strains criterion (see Method section). For instance, the minimum principal strain values were $-0.00087,-0.00129$ and -0.00072 for 4 -screw constructs $\mathrm{C} 4 \mathrm{~b}, \mathrm{C} 5 \mathrm{~b}$ and $\mathrm{C} 6 \mathrm{~b}$, respectively (Figure 5). In the 2-screw models (i.e. C6, $\mathrm{C} 7$ and $\mathrm{C} 8$ ), under $350 \mathrm{~N}$ axial compression load, the maximum principal strains were $\sim 0.001$ which is about 100 fold greater than the strains in the 4-screw constructs, but slightly less than the limit values $(\sim 0.0073)$ of the fracture criterion.

The prediction of maximum interfragmentary movement $(\mathrm{u})$, average of octahedral shear strain $\left(\varepsilon_{o c t}\right)$ and fluid velocity $\left(v^{f}\right)$ at the fracture site (scaffold) revealed that both the number and position of screws affect the 
(a)

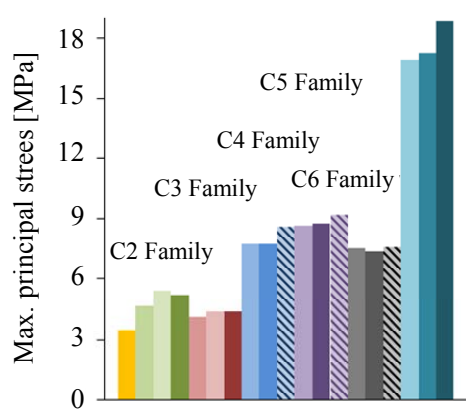

(c)

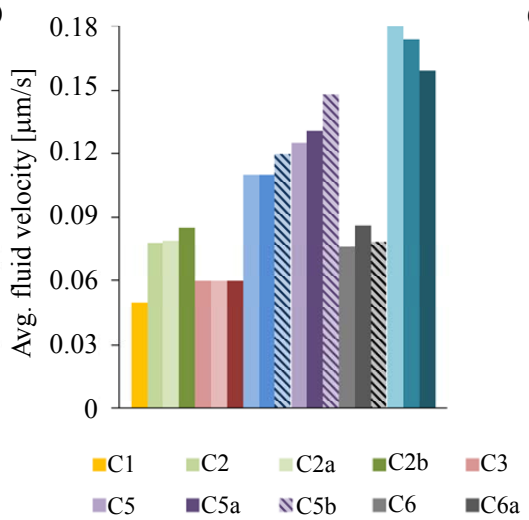

(b)

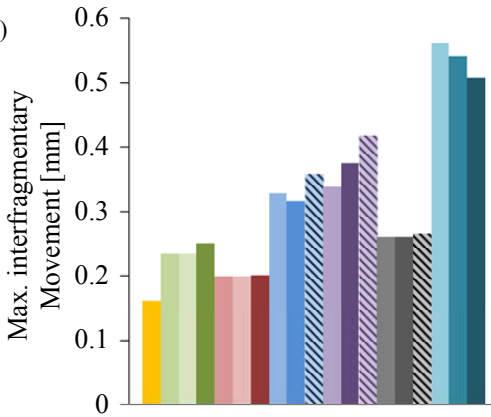

(d)

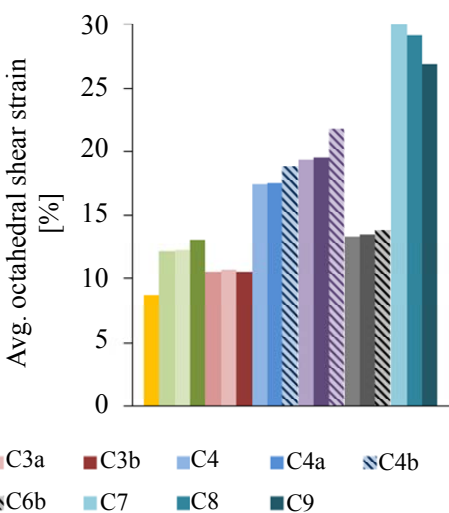

Figure 4. (a) The peak magnitudes of principal stress within the femur, (b) Maximum interfragmentary movement, (c) Average fluid velocity within the scaffold, and (d) Average octahedral shear strain within the scaffold.

(a)

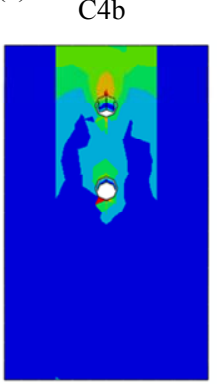

(b)

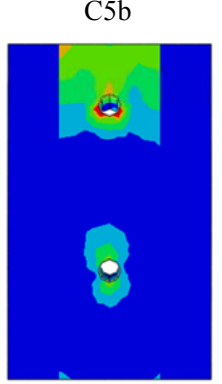

(c)

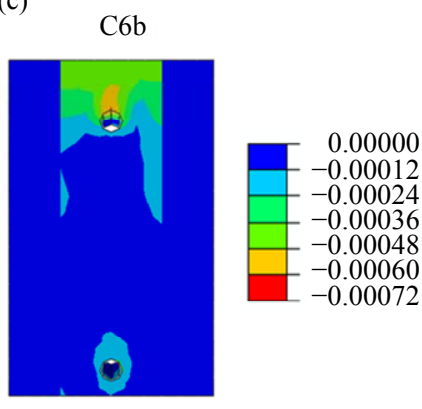

Figure 5. Distributions of principal strains within the midsection of the proximal femur are shown for (a) $\mathrm{C} 4 \mathrm{~b}$, (b) C5b and (c) C6b constructs. The scale bar is $5 \mathrm{~mm}$.

mechanical environment (Figures 4(b)-(d)). The fullyscrewed construct $\mathrm{C} 1$ and the family of $\mathrm{C} 3$ (7 and 6screw) had the smallest values of $\mathrm{u}, \varepsilon_{\text {oct }}$ and $v^{f}$ (average) among the constructs: $\sim 0.16 \mathrm{~mm}, 8.76 \%$ and 0.05 $\mu \mathrm{m} / \mathrm{s}$ for $\mathrm{C} 1$, and $\sim 0.2 \mathrm{~mm}, \sim 10.6 \%$ and $\sim 0.06 \mu \mathrm{m} / \mathrm{s}$ for the family of C3, respectively (Figures 4(b)-(d)). The average of the octahedral shear strain within the scaffold varied between $11.25 \%-22.5 \%$ for the family constructs C2 ( 12\% - 13\%), C4 ( 17\% - 18\%), C5 ( 19\% - 22\%) and C6 $(\sim 13 \%-14 \%)$ (Figure 4(d)). The scaffold in 2-screw constructs C7, C8 and C9 experienced significantly higher values of $\mathrm{u}, \varepsilon_{o c t}$ and $v^{f}$ compared to other constructs (Figures 4(b)-(d)): $30.65 \%, 0.182 \mu \mathrm{m} / \mathrm{s}$ and $0.56 \mathrm{~mm}$ for $\mathrm{C} 7,29.15 \%, 0.174 \mu \mathrm{m} / \mathrm{s}$ and $0.54 \mathrm{~mm}$ for C8, and $26.83 \%, 0.16 \mu \mathrm{m} / \mathrm{s}$ and $0.51 \mathrm{~mm}$ for C9.

\subsection{Simulation of Tissue Differentiation within the Nominated Constructs}

The stress-strain analyses (Figure 4) revealed that 4-screw constructs (C4b, C5b and C6b) had a load-support capability similar to constructs with higher screw numbers, and therefore, tissue differentiation was only predicted within the 4 -screw constructs $(\mathrm{C} 4 \mathrm{~b}, \mathrm{C} 5 \mathrm{~b}$ and $\mathrm{C} 6 \mathrm{~b})$. Over the 25 steps of simulation, the peak magni- 
tudes of average mechanical stimuli (octahedral strain and fluid velocity) were the highest $(22.3 \%, 1.54 \mu \mathrm{m} / \mathrm{s})$ for the $\mathrm{C} 5 \mathrm{~b}$, intermediate $(19.3 \%, 1.3 \mu \mathrm{m} / \mathrm{s})$ for the $\mathrm{C} 4 \mathrm{~b}$, and the lowest $(13.8 \%, 1.15 \mu \mathrm{m} / \mathrm{s})$ for the C6b construct (Figures 6(a) and (b)). After 25 weeks of healing, the maximum interfragmentary strain had converged to $0.33 \%$ for the $\mathrm{C} 5 \mathrm{~b}$ construct, whereas for the $\mathrm{C} 4 \mathrm{~b}$ and C6b constructs the interfragmentary strains were smaller at 0.26 and $0.14 \%$, respectively (Figure 6(a)). The fluid velocity increased and then gradually decreased and converged to a plateau of $0.8 \mu \mathrm{m} / \mathrm{s}$ (at week 16), 0.66 $\mu \mathrm{m} / \mathrm{s}$ (at week 18) and $0.6 \mu \mathrm{m} / \mathrm{s}$ (at week 11) for C5b, $\mathrm{C} 4 \mathrm{~b}$ and C6b, respectively (Figure 6(b)).

In all cases, bone formation was initiated from the core and regions of the scaffold closer to the plate (lateral)

(Figure 7). At week 8, looking at the cross-sections of the scaffolds (Figure 7), more bony tissue was present at the lateral side of C6b compared to C4b and C5b. The regions closer to the plate had an increased rate of healing compared to the outer regions (e.g., see weeks 4, 6, 8 and 10 for C6b Figure 7). As an example, for C6b, the inner core had differentiated into immature cartilage at week 4 (C6b, Figure 7), whereas the outer layer (medial) was still fibrous tissue. At week 6, the inner tissue had differentiated into mature cartilage and was mostly surrounded by immature cartilage (C6b, Figure 7). At week 8 , the core had differentiated into immature bone, whereas the outer layer was still cartilaginous (C6b, Figure 7).

At week 6, a considerable amount of granulation tissue was still present at the medial side of the scaffold for $\mathrm{C} 4 \mathrm{~b}$ and $\mathrm{C} 5 \mathrm{~b}$, compared with the C6b (Figure 7). A higher amount of cartilaginous tissue was predicted in $\mathrm{C} 5 \mathrm{~b}$ at week 25 of healing compared to other constructs (Figures 7(a)-(c)). The mineralization rate was the highest for $\mathrm{C} 6 \mathrm{~b}$, intermediate to $\mathrm{C} 4 \mathrm{~b}$ and the lowest for $\mathrm{C} 5 \mathrm{~b}$ (e.g., see Week 25 in Figures 7(a)-(c)). There was a gradual increase in the scaffold stiffness for all constructs over the healing period (Figure 6(c)). The predicted average elastic modulus was $2049 \mathrm{MPa}$ for $\mathrm{C} 4 \mathrm{~b}$ construct, $2800 \mathrm{MPa}$ for $\mathrm{C} 5 \mathrm{~b}$ and $3240 \mathrm{MPa}$ for C6b after $\sim 16,20$ and 14 weeks, respectively (Figure 6(c)).

\section{DISCUSSION}

The objective of the present study was to explore the effect of screw position on the fracture healing process in a plated transverse femoral fracture. An idealized 3D FE model of a fractured femur including a plate-screw construct was developed. To predict tissue differentiation over time, a biphasic mechanoregulatory algorithm [24], based on octahedral shear strain and interstitial fluid flow, was used. It was found that 4-screw constructs (i.e. C4b, $\mathrm{C} 5 \mathrm{~b}$ and $\mathrm{C} 6 \mathrm{~b}$ ) had adequate load-support capability (maximum difference ranging from $\sim 1$ to $10 \%$ was

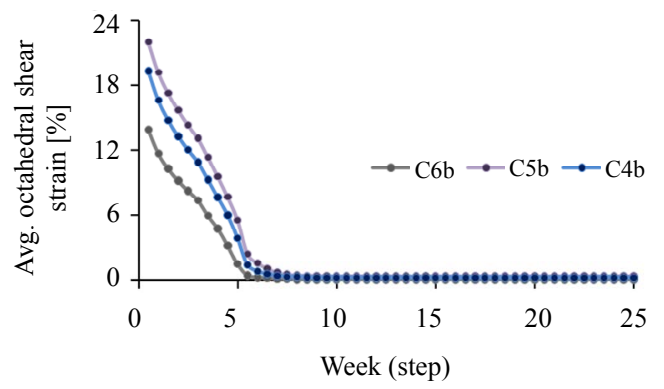

(a)

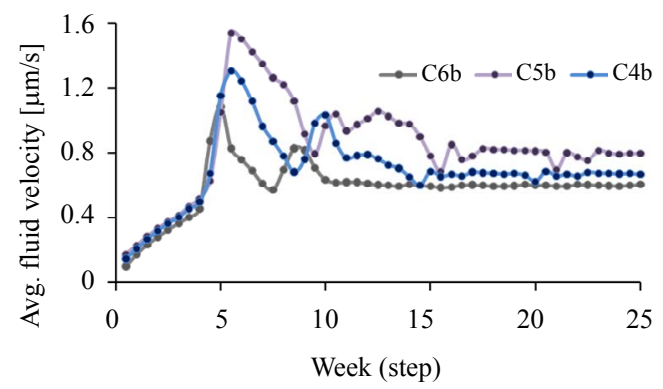

(b)

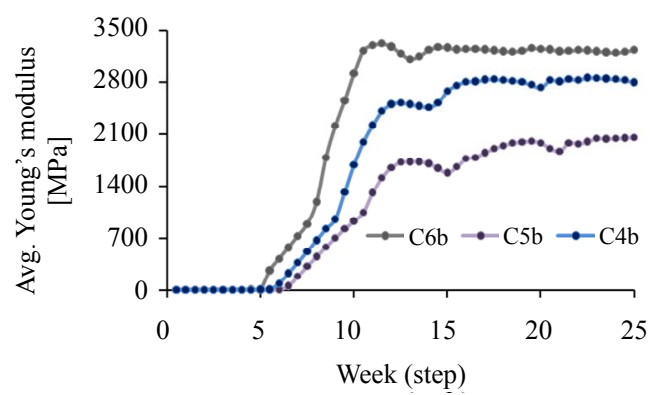

(c)

Figure 6. (a, b) Predicted average mechanical stimuli within the scaffold over time. The fracture within the $\mathrm{C} 5 \mathrm{~b}$ construct experienced the largest mechanical stimuli over the healing process within the scaffold. (c) The overall stiffness of the fracture site during the healing process for the $\mathrm{C} 4 \mathrm{~b}$, $\mathrm{C} 5 \mathrm{~b}$ and $\mathrm{C} 6 \mathrm{~b}$ constructs.

observed in each construct family) compared to the constructs with higher numbers of screws (Phase I). Although the load-support capability of 4-screw constructs was not significantly different, the position of the screws highly affected the temporal and spatial distribution of the differentiated tissues and the rate of healing (Phase II). The 4-screw construct C6b, with the maximum spacing between its screws, had the best balance of loadsupport capability, mechanical environment for bone formation and healing rate.

The constructs were initially analyzed to determine the model with the fewest screw numbers that still had sufficient load-support for the fracture. The stress analyses showed that the screws and plate experienced a higher magnitude of stress compared to the bone, which illustrates the stress shielding effect of the internal fixation 


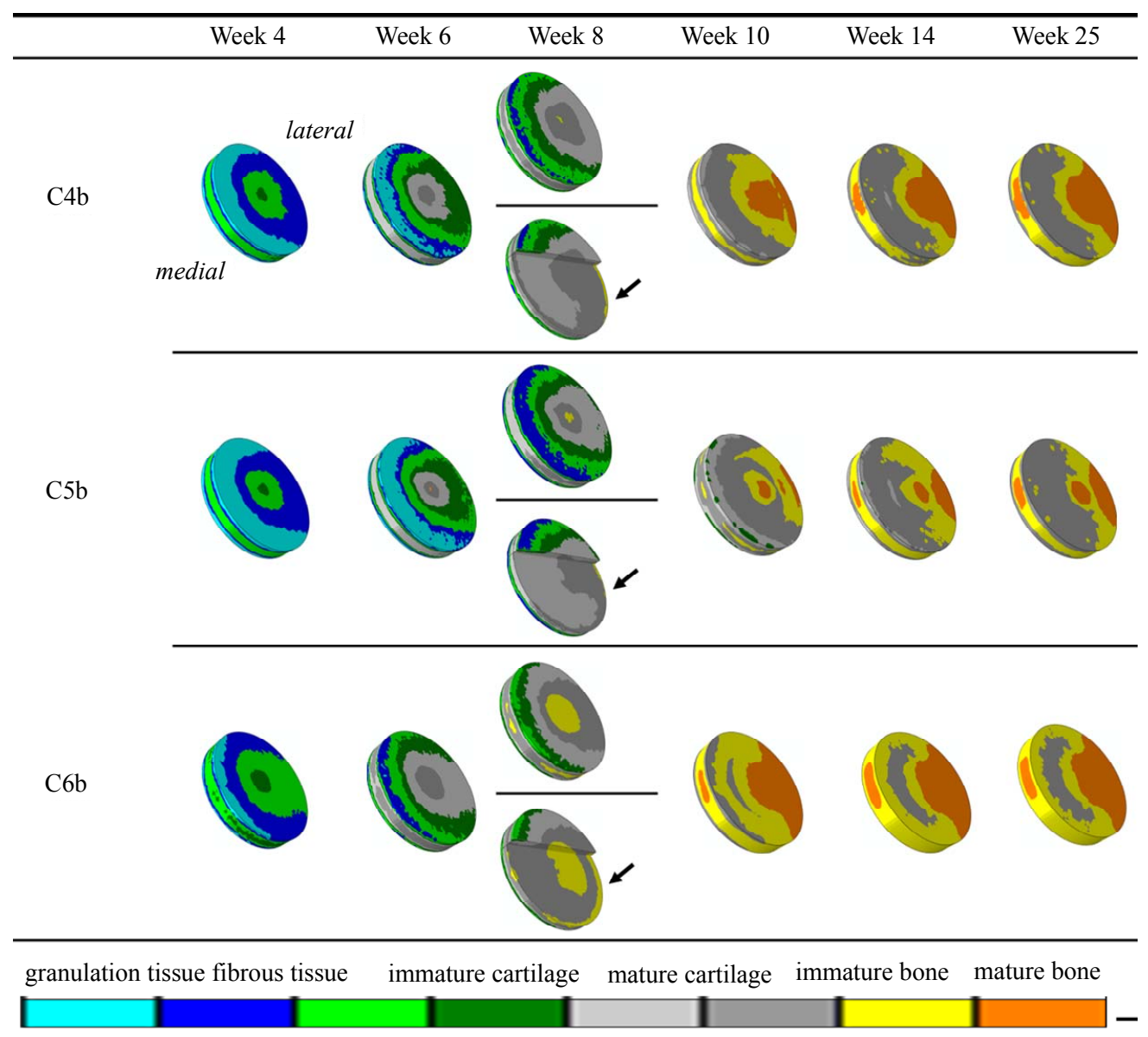

Figure 7. The predicted tissue formation pattern within the fracture for $\mathrm{C} 4 \mathrm{~b}, \mathrm{C} 5 \mathrm{~b}$ and $\mathrm{C} 6 \mathrm{~b}$ fixation cases. In all constructs, tissue differentiation is accelerated at the lateral side of the scaffold closest to the fixation compared to the medial side. The formation of bony tissue was initiated from the core and lateral side of the scaffold (see week 8 ). Scale bar is $5 \mathrm{~mm}$.

and the fact that fixation carried more load. Furthermore, the screws experienced a higher magnitude of stress compared to the plate which supports the clinical observation that screw breakages are more common than plate failures [55]. This was likely because the screws were in direct contact with the bone and transferred the load directly from the bone to the plate. This is also in agreement with the experimental/numerical study of Dubov et al. (2011) which found screw stresses were $\sim 30 \%$ greater than the plate in the optimal fixation construct. Furthermore, in both studies, the maximum stress in the plate was observed around the screw-holes in the vicinity of the gap, and the highest stress within the femur was found around the bone screw-holes [10]. The maximum displacement and strain within the scaffold occurred in the elements farthest from the bone plate (medial). This is consistent with the linear FE study of Kim et al. (2010) that also indicated a gradual increase in the strain values within the scaffold toward the opposite side of the bone plate [35].

The fixation of a fracture with a fully-screwed plate
(C1) significantly decreased the stress within the scaffold. However, a fully-screwed bone might be subjected to stress shielding. The interfragmentary motion is limited, but this may lead to less bone formation, higher bone resorption and consequently fixation loosening $[13,56$, 57]. Furthermore, the direct contact between the screws and bone might lead to disruption of the blood supply [58].

No significant difference was observed between the 8 and 7-screw constructs $(\mathrm{C} 1, \mathrm{C} 2$ and $\mathrm{C} 3$, Figure 4(a)). The stress distribution was also insensitive to the position of screws in the 8 and 7 -screw constructs $(\mathrm{C} 2$ and $\mathrm{C} 3$, Figure 4(a)). The magnitude of maximum principal strain within bone was less than the limit values defined by the strain criterion $[50,54]$. Therefore, it was concluded that the number of screws could be reduced. Four-screw constructs (e.g. C4b and C6b) were found to have almost the same load-support capability compared to 5 and 6-screw constructs (e.g. construct family of $\mathrm{C} 4$ and C6). The maximum difference between the predicted maximum von Mises stress within the 6-screw constructs 
(C4 and C6, with 25\% screw omission) and 4-screw constructs (C4b and C6b, with 50\% screw omission) were $\sim 10$ and $\sim 1.3 \%$, respectively. In particular, the construct $\mathrm{C} 6 \mathrm{~b}$ better distributed the strains throughout the femur. These predictions were in general agreement with the experiments of Field et al. (1999) on cadaveric bones, in which the omission of $25 \%-50 \%$ of the total screws did not affect the structural rigidity [12]. Furthermore, in the study of Dubov et al. (2011) [10], the construct with the largest distance between the screws above the fracture site (with a similar pattern to construct C6b in the present study) had the best load-support mechanism and showed minimum stress values in the bone. This was also in agreement with our results in which the bone in the 4-screw construct C6b experienced the least stress compared to 4 -screw constructs $\mathrm{C} 4 \mathrm{~b}$ and $\mathrm{C} 5 \mathrm{~b}$.

In each family of construct, the removal of $25 \%$ to $50 \%$ of the total number of screws (removal of two to four screws) did not change considerably the stress distribution within the femur. However, using fewer screws resulted in higher strain magnitudes within the fracture gap which may help the tissue differentiation process. These findings are in agreement with the studies of Korvick et al. (1988) and Field et al. (1999) that showed omission of $25 \%-50 \%$ of screws did not deleteriously affect the structural rigidity of the bone-plate assembly $[12,59]$. However, in certain assemblies, with all screws situated at both ends of the plate (similar to $\mathrm{C} 4 \mathrm{~b}$ in the present study) or with screws located at the ends of the plate as well as either side of the fracture gap (similar to $\mathrm{C} 6 \mathrm{~b}$ in the present study), then higher interfragmentary movement was observed. In these assemblies, the screw distribution led to an increase of strain within the fracture gap which could stimulate tissue differentiation [12,59]. According to the theory of Prendergast et al. (1997), the octahedral shear strain and fluid velocity to promote fibrous tissue differentiation and callus formation must satisfy this condition: $3<\frac{\varepsilon_{o c t}}{0.037}+\frac{v^{f}}{0.003} \leq 6 \quad[18,24,60]$. The average octahedral shear strain and fluid velocity within the scaffold of the 4-screw constructs (C4b, C5b and $\mathrm{C} 6 \mathrm{~b}$ ) were in the proposed range by Lacroix and Prendergast (Figures 4(c) and (d)). In contrast, the scaffold of the 2-screw constructs (C7, C8 and C9) had much higher strain magnitudes $(26 \%-30 \%$, Figures 4(c) and (d)), which were above the threshold values and thus the mechanical conditions were not conducive to bone formation. High strain values may cause cell apoptosis and delay the healing process [38-40]. Furthermore, the 4-screw constructs, will also have less contact surface compared to the constructs with higher number of screws (i.e. 5 to 8 -screw constructs) and consequently there would be less risk of blood supply disruption. The predicted magnitudes of strain and fluid velocity for these 4-scew structures were appropriate for tissue differentiation. Therefore, not only did 4-screw constructs $(\mathrm{C} 4 \mathrm{~b}$, $\mathrm{C} 5 \mathrm{~b}$ and $\mathrm{C} 6 \mathrm{~b}$ ) with a $50 \%$ screw omission have sufficient structural stability, they also provided favourable mechanical environment for bone formation.

Mechanical stimuli and tissue differentiation were predicted in the 4-screw constructs (C4b, C5b and C6b) over 25 weeks of healing. The predicted sequence of tissue regeneration in the femoral fracture model occurred in the same pattern observed in vivo $[61,62]$; bone formation was successfully simulated over time with the sequential prediction of fibrous, cartilage and bony tissue (endochondral ossification). At the initial stages of tissue formation, the stiffness of the scaffold was very low $(\sim 0.2-10 \mathrm{MPa})$, and the stress at the fracture site was relatively low. As an example, in the 4-screw construct C6b at week 4, the scaffold with the average stiffness of $\sim 4 \mathrm{MPa}$ (Figure 6c) had an average von Mises stress value as $\sim 0.13 \mathrm{MPa}$. As the scaffold stiffened over time, the stress carried by the bone was gradually transmitted to the scaffold, which resulted in an increase in the scaffold stress which decreased the stress shielding effect. For instance, in the 4-screw construct C6b, at week 8 the average of von Mises stress was $\sim 0.45 \mathrm{MPa}$ within the fracture site (average Young's modulus: $1189 \mathrm{MPa}$ ), whereas this value was only $\sim 1.15 \mathrm{MPa}$ at week 16 (average Young's modulus: $\sim 3250 \mathrm{MPa}$ ). In the final stages of healing, the variations of stress as well as the stiffness were negligible. For instance, the stiffness of the scaffold at week $16(3250 \mathrm{MPa})$ was not much different than the stiffness of the scaffold at week $20(3253 \mathrm{MPa})$, and consequently the von Mises stress carried by the fracture site remained unchanged $(\sim 1.15 \mathrm{MPa})$ between weeks 16 and 20 of healing. The linear FE study of Fouad (2010) predicted von Mises stresses at the fracture site at different healing stages. Consistent with our study, the value of von Mises stress within the fracture site at $50 \%$ healing was much greater than its value at initial stages of healing and the stress shielding effect decreased over time. Furthermore, in agreement with our study, the variation of von Mises stress and stiffness at the fracture site were predicted to remain constant at final stages of healing [13].

The magnitudes of local mechanical stimuli regulated the healing pathways within different regions of the scaffold. The differentiation of the bony tissue initiated from the regions that experienced less mechanical stimuli (e.g. the core and lateral side of the scaffold, Figure 7). Due to the plate-screw construct and model asymmetry, the geometric center of the bone shifted toward the plate. Therefore, the axial compressive load resulted in a marginal moment to the bone which was greater at the outer layer of the scaffold (medial). Hence, the outer layer of the scaffold was exposed to a higher range of mechanical 
stimuli and the time for the bone to heal was longer in that region. For instance, at week 4 , the octahedral shear strain and fluid velocity were $5.3 \%$ and $0.4 \mu \mathrm{m} / \mathrm{s}$, respectively, for an outer layer sample element, whereas these values were $2.1 \%$ and $0.1 \mu \mathrm{m} / \mathrm{s}$ at the core. These predictions are in agreement with the $\mathrm{X}$-ray observations of Fan et al. (2008) in which at 4 weeks after operation a stiffer callus was observed in the regions closer to the plate compared to the regions at the opposite side [63]. Furthermore, the histological slides from Uhthoff et al. (1983), in which the structural remodelling of 27 fractured femora was investigated, revealed that the osteons seemed more prominent under the stainless steel plates [64].

The general trend of tissue differentiation within the fracture was similar in the present study compared to the FE studies of Son et al. (2013) and Kim et al. (2012) that used an internal fixation for an idealized 3D long bone fracture. In the above-mentioned models, bone was subjected to a cyclic axial compression load at one end, while the other end was fixed. Similar to our predictions, bone healing was accelerated in the elements located closer to the plate and was delayed in the elements farther from the plate. Moreover, in agreement with the present study, the core of the scaffold was surrounded by softer tissues over the healing period. However, the spatial and temporal distributions were not identical, and overall, the healing was faster in their simulations compared to ours. The first difference that might have caused these variations was the use of different loading regimes. In our analysis, the applied load was $50 \%$ of the body weight, whereas in their studies it ranged between $10 \%$ $300 \%$ of the body weight. Secondly, in the current study, poroelastic material properties and a biphasic mechanoregulatory algorithm were implemented into our FE model, which means that the effect of fluid velocity was taken into account and tissue differentiation was reduced where fluid velocity was too high. On the other hand, linear elastic material properties and a single-solid phase algorithm, based solely on the strain, were used in the studies of Son et al. (2013) and Kim et al. (2012) to predict tissue differentiation. Hence, the effect of fluid velocity was neglected, which might have resulted in the faster healing rate [17].

The mechanical stimuli and consequently the healing progression were affected by the position of the screws (Figure 7). Among the 4-screw constructs, C6b had the highest healing rate, $\mathrm{C} 4 \mathrm{~b}$ intermediate and $\mathrm{C} 5 \mathrm{~b}$ the slowest (Figure 7). The delayed healing in 4-screw construct $\mathrm{C} 5 \mathrm{~b}$, with screws placed in the first, third, sixth and eighth screw holes, might result from lower stability, higher interfragmentary movement of the fracture gap, and higher mechanical stimuli within the scaffold over the healing period (Figures 6(a) and (b)). The predicted temporal stiffness of the scaffold again suggests that the gap in C6b, with the highest Young's modulus, was bridged more rapidly compared to $\mathrm{C} 4 \mathrm{~b}$ and $\mathrm{C} 5 \mathrm{~b}$ (Figure 6(c)). The stiffness of the scaffold in C6b converged to a plateau after 14 weeks of healing (3240 MPa for C6b); however, for $\mathrm{C} 4 \mathrm{~b}$ and $\mathrm{C} 5 \mathrm{~b}$ it took 2 and 6 weeks longer (2049 MPa for C4b and $2800 \mathrm{MPa}$ for C5b), respectively. The scaffold stiffness in our simulations (2049 MPa for C4b, $2800 \mathrm{MPa}$ for C5b and $3240 \mathrm{MPa}$ for C6b) and the stiffness predicted by Kim et al. (2012) using a stainless steel plate were in a similar range $(\sim 1750 \mathrm{MPa})$. The difference in the values may result from the fact that lower magnitudes of load were used in our simulations, which might lead to greater bone formation and a stiffer scaffold [20]. In other words, the higher stiffness in our models might be due to lower load magnitude $(50 \% \mathrm{BW})$ and consequently lower mechanical stimuli compared to Kim et al. where the bone was subjected to a load of $100 \% \mathrm{BW}$.

There were limitations associated with our computational study. The 3D idealized model used did not fully represent the exact geometry and loading on the femur. For instance, due to the natural curvature of the femur, the axial compression load applied to the cortical shaft induces combined compression and bending strains. Therefore, to ensure more accurate distributions of the tissue strain and stress, a 3D CT based FE model could be reconstructed in future studies. Moreover, only axial compressive load was applied to the model, whereas the simulation would be more realistic, if the forces and moments from the surrounding muscles were considered (e.g., better mimic a walking condition). The standard clinical treatment protocol would be none or partial weight bearing for $6-12$ weeks followed by full weight bearing. However, only a simple cyclic load was used since there is no clear consensus among surgeons, and weight bearing is often evaluated by the radiographic appearance of fracture. A simplified loading protocol allowed us to highlight the pure mechanical differences between constructs without the confounding effects of progressive weight bearing. In future research, we will focus on the experimental validation of the computational studies using gene expression patterns and highresolution $\mu \mathrm{CT}$ images of mineralization patterns.

\section{CONCLUSION}

This computational study has shown that the healing progression was greatly affected by the stability of the bone and the position of the screws. It was found that the symmetrical omission of $50 \%$ of the screws had almost the same load-bearing capability as the constructs with higher screw number. The 4-screw symmetrical construct $\mathrm{C} 6 \mathrm{~b}$, with the largest distance among the screws, of- 
fered the best bone-healing potential with sufficient stability at the fracture site. Using fewer screws provided the advantage of less damage to blood supply with an appropriate mechanical environment for tissue differentiation. Furthermore, the temporal increase of stress within the C6b scaffold (stiffness) may decrease the stress shielding effect and prevent focal bone loss and osteoporosis. It is our expectation that clinical application of the principles identified in this study may lead to less invasive surgical techniques that can maximize mechanical performance in the setting of minimal soft tissue injury.

\section{ACKNOWLEDGEMENTS}

Funding for this study was provided by the Natural Sciences and Engineering Research Council of Canada (NSERC).

\section{REFERENCES}

[1] Rockwood, C.A., Green, D.P. and Bucholz, R.W. (2010) Rockwood and Green's fractures in adults. Wolters Kluwer Health/Lippincott, Williams \& Wilkins, Philadelphia.

[2] Howard, A. and Giannoudis, P.V. (2012) Proximal femoral fractures: Issues and challenges. Injury, 43, 19751977. http://dx.doi.org/10.1016/j.injury.2012.09.013

[3] Sabharwal, S., Kishan, S. and Behrens, F. (2005) Principles of external fixation of the femur. American Journal of Orthopedics (Belle Mead NJ), 34, 218-223.

[4] Papini, M., Zdero, R., Schemitsch, E.H. and Zalzal, P. (2007) The biomechanics of human femurs in axial and torsional loading: Comparison of finite element analysis, human cadaveric femurs, and synthetic femurs. Journal of Biomechanical Engineering, 129, 12-19. http://dx.doi.org/10.1115/1.2401178

[5] Heineman, D.J., Poolman, R.W., Nork, S.E., Ponsen, K.J. and Bhandari, M. (2010) Plate fixation or intramedullary fixation of humeral shaft fractures. Acta Orthopaedica, 81, 216-223. http://dx.doi.org/10.3109/17453671003635884

[6] Einhorn, T.A. (1998) One of nature's best kept secrets. Journal of Bone and Mineral Research, 13, 10-12. http://dx.doi.org/10.1359/jbmr.1998.13.1.10

[7] Egermann, M., Goldhahn, J. and Schneider, E. (2005) Animal models for fracture treatment in osteoporosis, Osteoporosis International, 16, S129-S138. http://dx.doi.org/10.1007/s00198-005-1859-7

[8] Souna, B.S., Ganda, S., Amadou, S. and Abdoulaye, A. (2008) The treatment of tibia open fractures by Hoffmann external fixation in Niamey. About 50 cases. Mali Médical, 23, 11-15.

[9] Putnam, M.D. and Walsh, T.M.t. (1993) External fixation for open fractures of the upper extremity. Hand Clinics, 9, 613-623.

[10] Dubov, A., Kim, S.Y., Shah, S., Schemitsch, E.H., Zdero, R. and Bougherara, H. (2011) The biomechanics of plate repair of periprosthetic femur fractures near the tip of a total hip implant: The effect of cable-screw position. Proceedings of the Institution of Mechanical Engineers, Part $H, 225,857-865$. http://dx.doi.org/10.1177/0954411911410642

[11] Taljanovic, M.S., Jones, M.D., Ruth, J.T., Benjamin, J.B., Sheppard, J.E. and Hunter, T.B. (2003) Fracture fixation. Radiographics, 23, 1569-1590. http://dx.doi.org/10.1148/rg.236035159

[12] Field, J.R., Tornkvist, H., Hearn, T.C., Sumner-Smith, G. and Woodside, T.D. (1999) The influence of screw omission on construction stiffness and bone surface strain in the application of bone plates to cadaveric bone. Injury, 30, 591-598. http://dx.doi.org/10.1016/S0020-1383(99)00158-8

[13] Fouad, H. (2010) Effects of the bone-plate material and the presence of a gap between the fractured bone and plate on the predicted stresses at the fractured bone. $\mathrm{Me}$ dical Engineering \& Physics, 32, 783-789. http://dx.doi.org/10.1016/j.medengphy.2010.05.003

[14] Ramakrishna, K., Sridhar, I., Sivashanker, S., Khong, K.S. and Ghista, D.N. (2004) Design of fracture fixation plate for necessary and sufficient bone stress shielding. JSME International Journal Series C Mechanical Systems, Machine Elements and Manufacturing, 47, 1086-1094. http://dx.doi.org/10.1299/jsmec.47.1086

[15] Ganesh, V.K., Ramakrishna, K. and Ghista, D.N. (2005) Biomechanics of bone-fracture fixation by stiffnessgraded plates in comparison with stainless-steel plates. BioMedical Engineering OnLine, 4, 46. http://dx.doi.org/10.1186/1475-925X-4-46

[16] Carter, D.R., Vasu, R., Spengler, D.M. and Dueland, R.T. (1981) Stress fields in the unplated and plated canine femur calculated from in vivo strain measurements. Journal of Biomechanics, 14, 63-70. http://dx.doi.org/10.1016/0021-9290(81)90081-6

[17] Isaksson, H., Wilson, W., van Donkelaar, C.C., Huiskes, R. and Ito, K. (2006) Comparison of biophysical stimuli for mechano-regulation of tissue differentiation during fracture healing. Journal of Biomechanics, 39, 1507-1516. http://dx.doi.org/10.1016/j.jbiomech.2005.01.037

[18] Prendergast, P.J., Huiskes, R. and Soballe, K. (1997) ESB Research Award 1996. Biophysical stimuli on cells during tissue differentiation at implant interfaces. Journal of Biomechanics, 30, 539-548. http://dx.doi.org/10.1016/S0021-9290(96)00140-6

[19] Zhang, P. and Yokota, H. (2011) Knee loading stimulates healing of mouse bone wounds in a femur neck. Bone, 49 , 867-872.

[20] Gardner, M.J., van der Meulen, M.C., Demetrakopoulos, D., Wright, T.M., Myers, E.R. and Bostrom, M.P. (2006) In vivo cyclic axial compression affects bone healing in the mouse tibia. Journal of Orthopaedic Research, 24, 1679-1686. http://dx.doi.org/10.1002/jor.20230

[21] Carter, D.R., Blenman, P.R. and Beaupre, G.S. (1988) Correlations between mechanical stress history and tissue differentiation in initial fracture healing. Journal of Orthopaedic Research, 6, 736-748. http://dx.doi.org/10.1002/jor.1100060517

[22] Gardner, T.N., Stoll, T., Marks, L., Mishra, S. and Kno- 
the Tate, M. (2000) The influence of mechanical stimulus on the pattern of tissue differentiation in a long bone fracture-An FEM study. Journal of Biomechanics, 33, 415-425.

[23] Sandino, C. and Lacroix, D. (2011) A dynamical study of the mechanical stimuli and tissue differentiation within a $\mathrm{CaP}$ scaffold based on micro-CT finite element models. Biomechanics and Modeling in Mechanobiology, 10, 565-576. http://dx.doi.org/10.1007/s10237-010-0256-0

[24] Lacroix, D. and Prendergast, P.J. (2002) A mechanoregulation model for tissue differentiation during fracture healing: Analysis of gap size and loading. Journal of Biomechanics, 35, 1163-1171.

http://dx.doi.org/10.1016/S0021-9290(02)00086-6

[25] Isaksson, H., van Donkelaar, C.C., Huiskes, R. and Ito, K. (2006) Corroboration of mechanoregulatory algorithms for tissue differentiation during fracture healing: Comparison with in vivo results. Journal of Orthopaedic Research, 24, 898-907. http://dx.doi.org/10.1002/jor.20118

[26] Isaksson, H., van Donkelaar, C.C., Huiskes, R. and Ito, K. (2008) A mechano-regulatory bone-healing model incurporating cell-phenotype specific activity. Journal of Theoretical Biology, 252, 230-246.

[27] Checa, S. and Prendergast, P.J. (2009) A mechanobiological model for tissue differentiation that includes angiogenesis: A lattice-based modeling approach. Annals of Biomedical Engineering, 37, 129-145. http://dx.doi.org/10.1007/s10439-008-9594-9

[28] Checa, S. and Prendergast, P.J. (2010) Effect of cell seeding and mechanical loading on vascularization and tissue formation inside a scaffold: A mechano-biological model using a lattice approach to simulate cell activity. Journal of Biomechanics, 43, 961-968.

[29] McMahon, L.A., O'Brien, F.J. and Prendergast, P.J. (2008) Biomechanics and mechanobiology in osteochondral tissues. Regenerative Medicine, 3, 743-759. http://dx.doi.org/10.2217/17460751.3.5.743

[30] Nagel, T. and Kelly, D.J. (2010) Mechano-regulation of mesenchymal stem cell differentiation and collagen organisation during skeletal tissue repair. Biomechanics and Modeling in Mechanobiology, 9, 359-372. http://dx.doi.org/10.1007/s10237-009-0182-1

[31] Perez, M.A. and Prendergast, P.J. (2007) Random-walk models of cell dispersal included in mechanobiological simulations of tissue differentiation. Journal of Biomechanics, 40, 2244-2253.

[32] Prendergast, P.J., Checa, S. and Lacroix, D. (2010) Computational models of tissue differentiation. Springer Netherlands, Dordrecht, 353-372.

[33] Mehboob, H., Son, D.S. and Chang, S.H. (2013) Finite element analysis of tissue differentiation process of a tibia with various fracture configurations when a composite intramedullary rod was applied. Composites Science and Technology, 80, 55-65.

http://dx.doi.org/10.1016/j.compscitech.2013.02.020

[34] Son, D.S. and Chang, S.H. (2013) The simulation of bone healing process of fractured tibia applied with composite bone plates according to the diaphyseal oblique angle and plate modulus. Composites Part B: Engineering, 45,
1325-1335.

http://dx.doi.org/10.1016/j.compositesb.2012.07.037

[35] Kim, H.J., Chang, S.H. and Jung, H.J. (2012) The simulation of tissue differentiation at a fracture gap using a mechano-regulation theory dealing with deviatoric strains in the presence of a composite bone plate. Composites Part B: Engineering, 43, 978-987. http://dx.doi.org/10.1016/j.compositesb.2011.09.011

[36] Egol, K.A., Kubiak, E.N., Fulkerson, E., Kummer, F.J. and Koval, K.J. (2004) Biomechanics of locked plates and screws. Journal of Orthopaedic Trauma, 18, 488-493. http://dx.doi.org/10.1097/00005131-200409000-00003

[37] Kumar, A., Gupta, H., Yadav, C.S., Khan, S.A. and Rastogi, S. (2013) Role of locking plates in treatment of difficult ununited fractures: A clinical study. Chinese Journal of Traumatology, 16, 22-26.

[38] Kwong, F.N. and Harris, M.B. (2008) Recent developments in the biology of fracture repair. The Journal of the American Academy of Orthopaedic Surgeons, 16, 619625.

[39] Geris, L., Vandamme, K., Naert, I., Vander Sloten, J., Duyck, J. and Van Oosterwyck, H. (2009) Numerical simulation of bone regeneration in a bone chamber. Journal of Dental Research, 88, 158-163.

[40] Einhorn, T.A. (2005) The science of fracture healing. Journal of Orthopaedic Trauma, 19, S4-S6, 158-163.

[41] Miclau, T. and Martin, R.E. (1997) The evolution of modern plate osteosynthesis. Injury, 28, A3-A6. http://dx.doi.org/10.1016/S0020-1383(97)90109-1

[42] Karnezis, I.A., Miles, A.W., Cunningham, J.L. and Learmonth, I.D. (1998) "Biological" internal fixation of long bone fractures: A biomechanical study of a "noncontact" plate system. Injury, 29, 689-695. http://dx.doi.org/10.1016/S0020-1383(98)00168-5

[43] Edwards, W.B., Gillette, J.C., Thomas, J.M. and Derrick, T.R. (2008) Internal femoral forces and moments during running: Implications for stress fracture development. Clinical Biomechanics, 23, 1269-1278.

http://dx.doi.org/10.1016/j.clinbiomech.2008.06.011

[44] Taylor, M.E., Tanner, K.E., Freeman, M.A. and Yettram, A.L. (1996) Stress and strain distribution within the intact femur: Compression or bending? Medical Engineering \& Physics, 18, 122-131. http://dx.doi.org/10.1016/1350-4533(95)00031-3

[45] Aranzulla, P.J., Muckle, D.S. and Cunningham, J.L. (1998) A portable monitoring system for measuring weight-bearing during tibial fracture healing. Medical Engineering \& Physics, 20, 543-548. http://dx.doi.org/10.1016/S1350-4533(98)00061-7

[46] Riemer, B.L., Foglesong, M.E. and Miranda, M.A. (1994) Femoral plating. The Orthopedic Clinics of North America, 25, 625-633.

[47] Paterno, M.V. and Archdeacon, M.T. (2009) Is there a standard rehabilitation protocol after femoral intramedullary nailing? Journal of Orthopaedic Trauma, 23, S39S46. http://dx.doi.org/10.1097/BOT.0b013e31819f27c2

[48] Johnson, M.W., Chakkalakal, D.A., Harper, R.A., Katz, J.L. and Rouhana, S.W. (1982) Fluid flow in bone in vi- 
tro. Journal of Biomechanics, 15, 881-885. http://dx.doi.org/10.1016/0021-9290(82)90054-9

[49] Schaffler, M.B. and Burr, D.B. (1988) Stiffness of compact bone: Effects of porosity and density. Journal of Biomechanics, 21, 13-16. http://dx.doi.org/10.1016/0021-9290(88)90186-8

[50] Schileo, E., Taddei, F., Cristofolini, L. and Viceconti, M. (2008) Subject-specific finite element models implementing a maximum principal strain criterion are able to estimate failure risk and fracture location on human femurs tested in Vitro. Journal of Biomechanics, 41, 356-367. http://dx.doi.org/10.1016/j.jbiomech.2007.09.009

[51] Currey, J.D. (2012) The structure and mechanics of bone. Journal of Materials Science, 47, 41-54. http://dx.doi.org/10.1007/s10853-011-5914-9

[52] Jepsen, K.J. and Andarawis-Puri, N. (2012) The amount of periosteal apposition required to maintain bone strength during aging depends on adult bone morphology and tissue-modulus degradation rate. Journal of Bone and Mineral Research, 27, 1916-1926. http://dx.doi.org/10.1002/jbmr.1643

[53] Boskey, A.L. and Coleman, R. (2010) Aging and bone. Journal of Dental Research, 89, 1333-1348. http://dx.doi.org/10.1177/0022034510377791

[54] Bayraktar, H.H., Morgan, E.F., Niebur, G.L., Morris, G.E., Wong, E.K. and Keaveny, T.M. (2004) Comparison of the elastic and yield properties of human femoral trabecular and cortical bone tissue. Journal of Biomechanics, 37, 27-35. http://dx.doi.org/10.1016/S0021-9290(03)00257-4

[55] Stoffel, K., Dieter, U., Stachowiak, G., Gachter, A. and Kuster, M.S. (2003) Biomechanical testing of the LCPhow can stability in locked internal fixators be controlled? Injury, 34, 11-19. http://dx.doi.org/10.1016/j.injury.2003.09.021

[56] Uhthoff, H.K., Poitras, P. and Backman, D.S. (2006) Internal plate fixation of fractures: Short history and recent developments. Journal of Orthopaedic Science, 11, 118-126. http://dx.doi.org/10.1007/s00776-005-0984-7
[57] Huiskes, R., Weinans, H., Grootenboer, H.J., Dalstra, M., Fudala, B. and Slooff, T.J. (1987) Adaptive bone-remodeling theory applied to prosthetic-design analysis. Journal of Biomechanics, 20, 1135-1150. http://dx.doi.org/10.1016/0021-9290(87)90030-3

[58] Noor, S., Pridham, C., Fawcett, T., Barclay, M., Feng, Y. T., Hassan, O. and Pallister, I. (2013) Finite element analysis modelling of proximal femoral fractures, including post-fixation periprosthetic fractures. Injury, 44, 791-795. http://dx.doi.org/10.1016/j.injury.2012.10.023

[59] Korvick, D.L., Monville, J.D., Pijanowski, G.J. and Phillips, J.W. (1988) The effects of screw removal on bone strain in an idealized plated bone model. Veterinary Surgery, 17, 111-116. http://dx.doi.org/10.1111/j.1532-950X.1988.tb00288.x

[60] Lacroix, D. (2000) Simulation of tissue differentiation during fracture healing. Ph.D. Dessertation, University of Dublin, Dublin.

[61] Bailon-Plaza, A. and van der Meulen, M.C. (2001) A mathematical framework to study the effects of growth factor influences on fracture healing. Journal of Theoretical Biology, 212, 191-209.

http://dx.doi.org/10.1006/jtbi.2001.2372

[62] Gerstenfeld, L.C., Cullinane, D.M., Barnes, G.L., Graves, D.T. and Einhorn, T.A. (2003) Fracture healing as a post-natal developmental process: Molecular, spatial, and temporal aspects of its regulation. Journal of Cellular Biochemistry, 88, 873-884. http://dx.doi.org/10.1002/jcb.10435

[63] Fan, Y., Xiu, K., Duan, H. and Zhang, M. (2008) Biomechanical and histological evaluation of the application of biodegradable poly-L-lactic cushion to the plate internal fixation for bone fracture healing. Clinical Biomechanics, 23, S7-S16. http://dx.doi.org/10.1016/j.clinbiomech.2008.01.005

[64] Uhthoff, H.K. and Finnegan, M. (1983) The effects of metal plates on post-traumatic remodelling and bone mass. The Journal of Bone and Joint Surgery, 65, 66-71. 